\title{
Modeling the Ecological and Phenological Predictors of Fruit Consumption by Gibbons (Hylobates albibarbis)
}

\author{
Christopher Dillis ${ }^{1,2,6}$, Lydia Beaudrot ${ }^{2,3}$, Katie L. Feilen², Dena J. Clink ${ }^{2}$, Heiko U. Wittmer ${ }^{4}$, and Andrew J. Marshall ${ }^{1,2,3,5}$ \\ ${ }^{1}$ Animal Behavior Graduate Group, University of California-Davis, One Shields Avenue, Davis, CA 95616, U.S.A. \\ ${ }^{2}$ Department of Anthropology, University of California-Davis, One Shields Avenue, Davis, CA 95616, U.S.A. \\ ${ }^{3}$ Graduate Group in Ecology, University of California-Davis, One Shields Avenue, Davis, CA 95616, U.S.A. \\ ${ }^{4}$ School of Biological Sciences, Victoria University of Wellington, PO Box 600, Wellington 6140, New Zealand \\ ${ }^{5}$ Current address: Department of Anthropology, University of Michigan, 1085 S. University Ave, Ann Arbor, MI 48109, U.S.A.
}

\section{ABSTRACT}

Understanding the ecological interactions between plant reproductive strategies and frugivore feeding behavior can offer insight into the maintenance of tropical forest biodiversity. We examined the role of plant ecological and phenological characteristics in influencing fruit consumption by the White-bearded gibbon (Hylobates albibarbis) in Gunung Palung National Park, Indonesian Borneo. Gibbons are widespread across Borneo, highly frugivorous and perform important seed dispersal services. We compare multiple models using information criteria to identify the ecological and phenological predictors that most strongly influence gibbon fruit use of 154 plant genera. The most important predictors of resource use were the overall abundance of a genus and the consistency of fruit availability. Plant genera can maintain constant fruit availability as a result of (1) individual stems fruiting often or (2) stems fruiting out of synchrony with each other (asynchrony). Our results demonstrate that gibbons prefer to feed on plant genera that provide consistent fruit availability due to fruiting asynchrony. Because gibbons feed more often on genera that fruit asynchronously, gibbons are more likely to disperse seeds of plant genera with this reproductive strategy. Research on other frugivorous species is needed to determine whether the results for gibbons are generalizable more broadly. Finally, these results suggest that asynchronously fruiting plant genera may be particularly important for habitat restoration in tropical forests designed for frugivore conservation.

Abstract in Indonesian is available in the online version of this article.

Key words: foraging strategy; frugivory; fruiting asynchrony; Indonesia; phenology; tropical ecology; vertebrate feeding ecology.

Mutualistic INTERACTIONS BETWEen TREes THAT PRODUCE FLESHY FRUITS AND THE frugivores that disperse their seeds are widespread in forest ecosystems and contribute to the maintenance of biodiversity (McKey 1975, Terborgh et al. 2002). Animal-mediated dispersal is the most common means of seed dispersal for angiosperms in tropical forests, comprising 50-75 percent of tropical tree species (Howe \& Smallwood 1982, da Silva \& Tabarelli 2000). It is therefore unsurprising that there has been a considerable amount of interest in identifying the qualities of fruits and fruiting plants that predict use by frugivores. Research aimed at predicting fruit use has involved both the physiological and morphological traits of the fruits themselves Janson 1983, Fischer \& Chapman 1993, Leighton 1993, McConkey et al. 2002) as well as general ecological and phenological characteristics of woody angiosperms (e.g., spatial and temporal abundance (McConkey et al. 2003, Walker 2007, Felton et al. 2008), crop size (Leighton 1993, Korine et al. 2000), and fruiting synchrony (Fredriksson \& Wich 2006) or asynchrony (Poulin et al. 1999)).

Received 13 December 2013; revision accepted 15 September 2014.

${ }^{6}$ Corresponding author; e-mail: cdillis@ucdavis.edu
Studies examining the role of fruit morphology and chemistry in determining use by frugivores have determined that commonly eaten fruits are often similar in their macronutrient balance (Conklin-Brittain et al. 1998, Felton et al. 2009), chemical defenses (Cipollini \& Levey 1997, Wrangham et al. 1998), and morphological characteristics (e.g., size and color; Fischer \& Chapman 1993, Korine et al. 2000, Terborgh et al. 2002, Stevenson \& Link 2010). Indeed a number of studies have hypothesized distinct plant 'dispersal syndromes' based on a correspondence between the morphology and chemistry of fruits and the anatomies and preferences of their putative vertebrate dispersers. Dispersal syndrome patterns have been identified in site-specific field studies (Knight \& Siegfried 1983, Gautier-Hion et al. 1985, Lomáscolo et al. 2010). Broad spatial patterns in plant and animal distributions reflecting dispersal syndromes have also been found (Voigt et al. 2004, Almeida-Neto et al. 2008, Beaudrot et al. 2013).

In contrast with the breadth of studies of fruit traits, research on the ecological characteristics of plants important to frugivores has often been confined to a single characteristic or has focused on a single plant taxon. Nevertheless, several areas of research have demonstrated that general ecological characteristics of fruiting plants can strongly influence frugivore diets (van 
Schaik et al. 1993, Burns 2004, Thies \& Kalko 2004, Hanya 2005). For instance, it is known that taxa with large crop sizes are preferred by several tropical bird and bat species (Korine et al. 2000, Blendinger \& Villegas 2011). Additionally, spatial abundance of a plant species at multiple scales is known to influence avian frugivore foraging (Garcia \& Ortiz-Pulido 2004, Carlo \& Morales 2008). Finally, plants that stagger fruiting times across individuals (such as figs [Ficus: Moraceae]) play important roles as keystone resources for many tropical frugivores, given their constant availability (Janzen 1979, Terborgh 1983, Lambert \& Marshall 1991, van Schaik et al. 1993, Marshall \& Wrangham 2007).

Despite the importance of specific ecological characteristics of fruiting plants for predicting frugivore use, to date few studies have considered multiple ecological characteristics simultaneously or examined patterns across broad taxonomic groups (Fleming 1992, Leighton 1993). As a result, we know little about the relative importance of ecological characteristics in determining fruit consumption and whether these patterns are consistent across plant taxa in diverse communities. Identification of patterns such as these will inform our understanding of frugivore foraging strategies, as well as their implications for animal-dispersed plant species.

Primates comprise a major proportion of biomass of the frugivorous vertebrates found on the island of Borneo in Southeast Asia (MacKinnon et al. 1996, Primack \& Corlett 2005). Furthermore, of the 13 primate species found on Borneo, gibbon diets contain the highest percentage of fruit (Gupta \& Chivers 1999). Moreover, gibbons have been documented to feed on a wide variety of plant taxa (Marshall et al. 2009b). Gibbons therefore provide an excellent taxon in which to investigate the role of ecological plant characteristics in predicting frugivore use. Additionally, the high plant diversity in Southeast Asian forests provides many genera of available fruit resources (Kier et al. 2005) encompassing a wide range of phenological patterns (Van Schaik 1986, Marshall \& Leighton 2006). Moreover, there are significant temporal fluctuations in fruit availability, with highly productive, aseasonal masting events separated by periods of general fruit scarcity (Wich \& van Schaik 2000, Marshall \& Leighton 2006, Cannon et al. 2007a), which produce a wide range of ecological conditions to which frugivores must adapt.

In this study, we examine the relative importance of multiple ecological and phenological characteristics of plants in influencing consumption by frugivorous White-bearded gibbons (Hylobates albibarbis) in Indonesian Borneo. Considering the wide range of plant taxa known to be consumed by co-occurring frugivorous vertebrates in Borneo, we address questions including: (1) does the amount of fruit that a plant produces, as estimated by its diameter at breast height (dbh) and crop size, predict consumption? (2) Does the density of stems of a genus (which reflects the commonness throughout the landscape) or the frequency with which individual stems fruit strongly affect use? (3) Does temporal clustering of fruiting events or timing of reproductive bouts relative to the rest of the forest affect which taxa are more likely to be consumed? We address these questions by quantifying ecological and phenological characteristics of 154 plant genera. We then use an information theoretic approach to identify which predictors most strongly influence gibbon fruit use by comparing multiple models using AICc model selection.

\section{MATERIALS AND METHODS}

FIELD SITE.-Our study was conducted at the Cabang Panti Research Station (CPRS) in Gunung Palung National Park, West Kalimantan $\left(1^{\circ} 13^{\prime} \mathrm{S}, 110^{\circ} 7^{\prime} \mathrm{E}\right)$. The study site contains seven distinct forest types that differ due to variations in soil type, drainage, altitude, and underlying geology (Paoli et al. 2006, Marshall 2009, 2010, Marshall et al. 2014). Phenological patterns in two of the seven forest types, montane and peat swamp forests, differ dramatically from the five other forest types found at the site (Marshall \& Leighton 2006, Cannon et al. 2007a,b). We therefore restricted our analysis to feeding observations and phenological data from the following five forest types: freshwater swamp, alluvial bench, lowland sandstone, lowland granite, and upland granite. Although there may be interesting differences among these habitats in the ecological characteristics we considered, we did not have a sufficient number of feeding observations in each habitat to permit robust analyses at the level of forest type. We present data on plant phenology and gibbon feeding collected between October 2007 and February 2013.

Plant data collection and analysis.-We used a random number generator to select ten plant phenology plots in each forest type from among the 126 that were randomly placed at the site in the mid 1980s by M. Leighton and colleagues (Cannon \& Leighton 2004, Cannon et al. 2007b). The locations of the plots in each forest type were determined initially using a random number generator to select co-ordinates and bearings for each (M. Leighton, pers. comm.). Plots were either 0.1 or 0.2 ha in size and sampling area totaled 1.5 ha per forest type. In these plots, trees larger than $14.5 \mathrm{~cm}$ dbh, all lianas larger than $3.5 \mathrm{~cm}$ $\mathrm{dbh}$, and all hemi-epiphytic figs whose roots reached the ground were identified, measured, and tagged (see Marshall \& Leighton 2006, Marshall 2004, 2010 for details). As a result of our dbh cutoff, smaller trees and understory shrubs were excluded from the analysis. We retagged and recorded the locations of all stems in the seventy plots in 2007. Botanical nomenclature followed APGII (Angiosperm Phylogeny Group 2003). We monitored monthly the reproductive behavior of all tagged tree, fig, and liana stems located in the phenology plots (mean stems $/ \mathrm{mo}=3050$; $\mathrm{SD}=464)$. We carefully examined each stem with binoculars and assigned it to one of six reproductive states: reproductively inactive, bearing flower buds, flowers, immature, mature, or ripe fruits. We used changes in fruit size, color, and texture to determine ripeness stages for each plant taxon, following categories developed over the last $20 \mathrm{yr}$ (Cannon et al. 2007b, Marshall et al. 2009 b). If the stem was reproductively active, we assessed the total crop size using a semi-logarithmic scale to avoid compounding errors at large crop sizes (Marshall \& Wich 2013).

We conducted all analyses at the generic level. While there are species-specific differences in plant phenology and fruit traits, 
demonstration of phylogenetic conservatism at the genus level has called into question the appropriateness of broad comparative analyses at the species level, due to statistical non-independence (Harvey \& Pagel 1991, Kelly \& Purvis 1993, Chazdon et al. 2003, Davies et al. 2013). In addition, Bornean forests contain some of the highest levels of vascular plant diversity in the world (Kier et al. 2005). As a consequence, despite extensive sampling and many voucher specimen collections, a considerable proportion of the flora have yet to receive formal taxonomic treatment in the scientific literature and were therefore only identified to the genus level.

We calculated model predictors for each plant genus $(N=154)$ that fruited at least once during the 66-mo study period and that was observed to have been fed upon at least once by a vertebrate at CPRS (Blundell 1996, Laman et al. 1996, Marshall et al. 2009b). In addition to including model predictors for each genus for growth form (i.e., tree, liana), crop size, and $d b h$, we also calculated several predictors to take into account the commonness of a genus across the landscape and its fruit availability over time. To balance sample sizes among categories and thereby facilitate robust analysis, crop size was organized into four discrete categories: I (1-25 fruits), II (26-100 fruits), III (101500 fruits), IV ( $>500$ fruits). Due to concerns that this categorical approach may have been overly conservative (and insufficient to reveal correlations between crop size and other continuous predictors), we also included $d b h$ as a continuous proxy variable for crop size (Chapman et al. 1992, Leighton 1993, Marshall \& Wich 2013). Stem density was defined as the average number of stems of the focal genus per ha. Fruit frequency was defined as the average proportion of months in the study that a stem of the focal genus produced fruit. Productivity was defined as the average proportion of all plants (focal genus excluded) in fruit during the months in which the focal genus fruited. Synchrony was defined as the temporal clustering of fruiting by individuals within the focal genus, calculated as the coefficient of variation of number of individuals in fruit during each month of the study. Rainfall was defined as the mean daily rainfall during the months in which the focal genus fruited (Table 1). For clarity, model predictors are indicated by italics throughout.

GibBOn FEEDING OBSERVATIONS.-We observed the feeding behavior of $H$. albibarbis along standardized vertebrate survey transects and during focal follows (see Marshall 2010, Marshall et al. 2009b for details). Mean monthly survey effort across the five forest types sampled was $61.45 \mathrm{~km} / \mathrm{mo}(\mathrm{SD}=2.73 \mathrm{~km})$. In addition to gathering standard line-transect data (Buckland et al. 2001, 2010), whenever we encountered a group of $H$. albibarbis feeding, the following data on the plant fed upon by the first primate individual sighted were collected: the identification (to the lowest taxonomic level possible), location (using a GPS unit or detailed address from the trail), $d b h$, and growth form (e.g., tree, liana, hemiepiphytic fig) of the plant; the part being eaten (e.g., fruit pulp, seeds, young leaves); the maturity stage, if applicable (e.g., immature, ripe); the number of animals feeding; and an estimate of the total crop size (Marshall 2004, Marshall \& Leighton 2006). Follow-
TABLE 1. Description of predictors used in models of Hylobates albibarbis foraging behavior.

\begin{tabular}{|c|c|}
\hline Predictor & Description \\
\hline Form & $\begin{array}{l}\text { Plant growth form: tree or liana (Ficus categorized as a } \\
\text { liana) }\end{array}$ \\
\hline Crop Size & $\begin{array}{l}\text { Average \# of fruits per crop of genus } i \text { in four ordered } \\
\text { categories: I(1-25 fruits), II(26-100 fruits), III(101-500 } \\
\text { fruits), IV(>500 fruits) }\end{array}$ \\
\hline Dbh & Average stem diameter at breast height of genus $i$ \\
\hline Stem density & Stems per hectare of genus $i$ \\
\hline Fruit Frequency & $\begin{array}{l}\text { Proportion of months in fruit for an average stem of } \\
\text { genus } i\end{array}$ \\
\hline Synchrony & $\begin{array}{l}\text { Temporal overlap of fruiting stems of genus } i \text { (calculated } \\
\text { as the coefficient of variation of the vector of \# fruiting } \\
\text { stems per month) }\end{array}$ \\
\hline Productivity & $\begin{array}{l}\text { Average proportion of all stems in forest in fruit during } \\
\text { months in which genus } i \text { fruited }\end{array}$ \\
\hline Rainfall & $\begin{array}{l}\text { Average daily rainfall }(\mathrm{cm}) \text { during months in which genus } \\
i \text { fruited }\end{array}$ \\
\hline
\end{tabular}

ing collection of these data, we continued observations along the vertebrate survey route, so multiple feeding observations were not made from the same group on the same day. Therefore, we considered all feeding observations recorded along transects as independent measures of intake. The probability of observing feeding on a particular genus was proportional to the proportion of time that gibbons spent feeding on it, therefore these independent measures gathered along survey routes reflect overall diet composition (i.e., proportions of feeding time spent eating each genus).

We collected additional feeding data during the course of targeted focal observations. Target groups were selected at random from among the known groups at the site (during the research period $N=20-28$ groups, located across the full range of forest types). After contacting the target group, we randomly selected a focal individual and followed until it began feeding. The same feeding data were gathered as were collected on census routes and data collection continued for $30 \mathrm{~min}$, at which point a new focal individual was randomly chosen. Feeding by the new focal animal was not recorded until it had travelled to a different tree or liana to ensure that multiple feeding observations were not recorded from the same individual plant.

We gathered one feeding observation every $3.6 \mathrm{~d}$ (duration between successive feeding observations varied from 0 to $68 \mathrm{~d}$, $\mathrm{SD}=6.3$ ). We found no significant difference in use of plant genera between data gathered on follows and those gathered on census routes $(N=154$, Mann Whitney $U=11,857, P=0.99)$, and therefore they were lumped in order to increase sample size.

ECOLOGICAL PREDICTORS OF FRUIT CONSUMPTION.-We created 20 models (including an intercept model) predicting use (number of feeding observations for each genus) of a given plant genus based on a set of candidate predictor variables, reflecting hypotheses about which variables influenced gibbon fruit consumption 
(Table S1). We compared these models using an information theoretic approach based on Akaike's Information Criterion (AICc, corrected for small sample sizes; Burnham \& Anderson 2002). All models were fit using a negative-binomial distribution, which incorporates an additional parameter $(\theta)$ to account for over-dispersed count data. They were therefore generalized linear regression models, using a log link function. Because raw values of the continuous predictor variables were on scales that differed by orders of magnitude, they were log-transformed in order to facilitate compatible scaling, variance stabilization, and use of a GLM with a log-link. Models were evaluated using AICc model comparison and averaging (Johnson \& Omland 2004) using the MuMIn package (Bartoń 2012) in R (R Development Core Team 2012) to produce estimates of predictors within an averaged model. Estimates of predictors were considered reliable if $95 \%$ confidence intervals did not overlap zero.

\section{RESULTS}

VARIABILITY IN PLANT ECOLOGICAL AND PHENOLOGICAL CHARACTERISTICS.-We examined the correlation among variables prior to model fitting to determine whether any were highly correlated, which may have produced inaccurate model results. There were no strong correlations between continuous predictors (maximum $r=-0.44$; Table S2).

There was a large amount of variation in ecological and phenological predictor values (Table 2) across the 154 plant genera included in this study (Table S3). For instance, spatial and temporal abundance varied by orders of magnitude, as did average crop sizes. There was also a large range of stem sizes within both trees $($ mean $=30.4 \pm \mathrm{SD}=15.7 \mathrm{~cm})$ and lianas $($ mean $=5.5$ $\pm \mathrm{SD}=0.5 \mathrm{~cm}$ ). Stem density ranged from 0.1 to 27.1 stems per ha (mean $=2.5 \pm \mathrm{SD}=3.6$ stems per ha). Fruit frequency ranged from 0.0005 to 0.33 (mean $=0.05 \pm \mathrm{SD}=0.06$ ). Productivity ranged from 0.02 to 0.09 (mean $=0.05 \pm \mathrm{SD}=0.01$ ), while synchrony ranged from 46.4 to 806.2 (mean $=273.6 \pm \mathrm{SD}=189.4)$. The distributions of these values were similar between plant genera that were consumed versus those that were unused by gibbons, with the exception of the shape of the distributions for synchrony and stem density (Fig. 1). Gibbons fed on genera with higher stem densities and lower synchrony values.

TABLE 2. Mean and standard deviation of predictors for all genera (column 2), and subset of those genera unused (column 3) and used (column 4) by gibbons.

\begin{tabular}{lccc}
\hline Predictors & All genera & Unused genera & Used genera \\
\hline Fruit frequency & $0.05 \pm 0.06$ & $0.05 \pm 0.06$ & $0.06 \pm 0.06$ \\
Stem density & $2.48 \pm 3.57$ & $1.94 \pm 2.97$ & $4.32 \pm 4.72$ \\
Mean productivity & $0.05 \pm 0.01$ & $0.05 \pm 0.01$ & $0.05 \pm 0.01$ \\
Synchrony & $277.05 \pm 191.94$ & $303.00 \pm 195.50$ & $188.83 \pm 150.86$ \\
DBH & $24.84 \pm 16.37$ & $24.48 \pm 15.55$ & $26.05 \pm 19.10$ \\
Mean rainfall & $11.63 \pm 2.45$ & $11.60 \pm 2.46$ & $11.72 \pm 2.45$ \\
Mean richness & $52.81 \pm 8.70$ & $53.09 \pm 9.23$ & $51.85 \pm 6.59$ \\
\hline
\end{tabular}
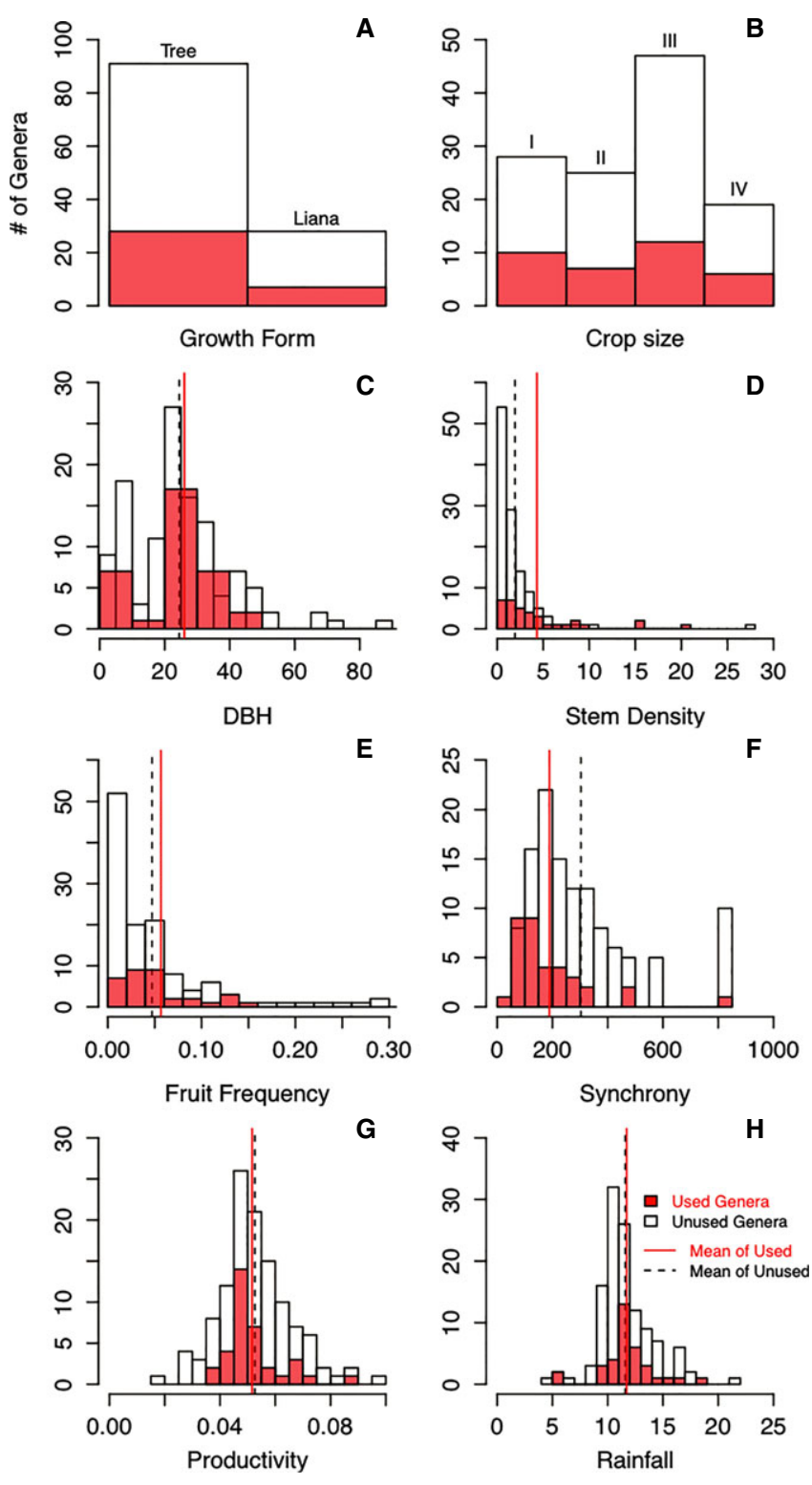

FIGURE 1. Histograms of model predictors, divided into genera used (shown in red) and unused (shown in white) by gibbons. Vertical lines depict means of continuous predictor variables for used (solid red) and unused (dashed black) genera.

There was significant temporal variation in the overall availability of fruiting stems (Fig. 2A). There were also differences among genera in synchrony and fruit frequency of individual stems, resulting in distinct phenological patterns (Figs. 2B, C and D). Stems of some genera, such as Ochanostachys (Olacaceae) produced fruit as often as the overall average (Ochanostachys fruit frequency $=0.04$, overall genera mean fruit frequency $=0.05$ ), while confining fruiting to only several months, resulting in a high synchrony value $(\mathrm{CV}=295.8$; Fig. $2 \mathrm{~B})$. In contrast, other genera such as Girroniera (Ulmaceae, Fig. 2C) and Artabotrys (Annonaceae, Fig. 2D) produced fruit in almost every month. Unlike Girroniera 


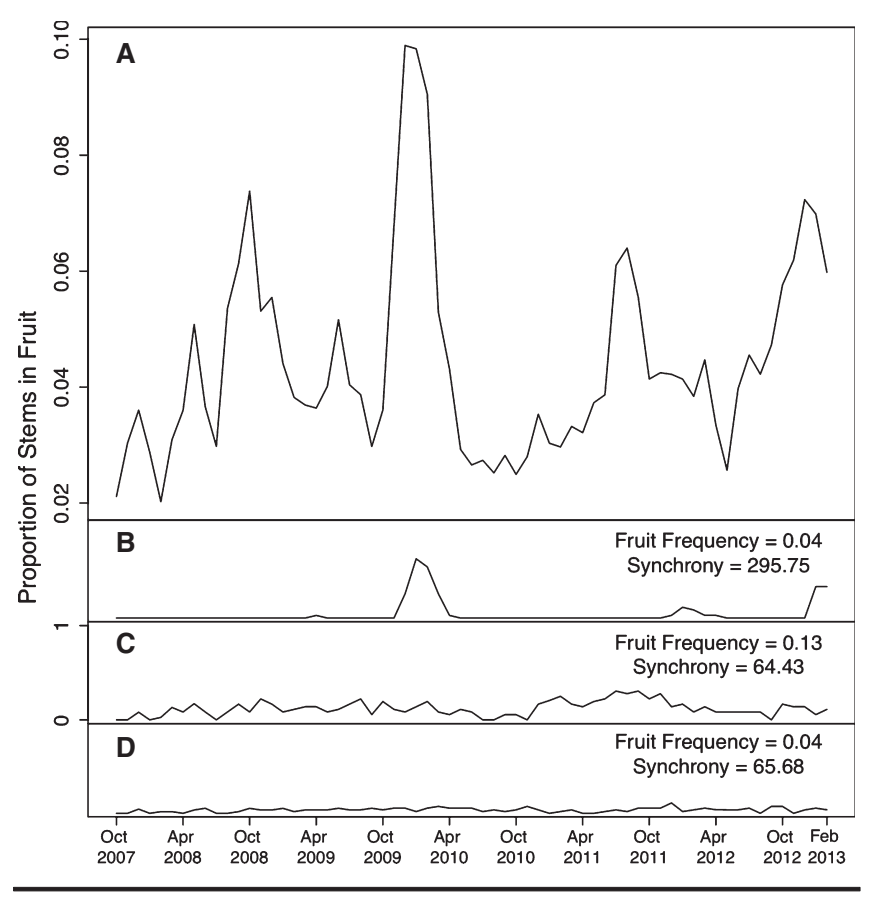

FIGURE 2. Plot of general forest productivity illustrating the proportion of the overall number of stems in the forest bearing fruit over time (A), as well as fruiting profiles of three genera representing prototypical phenological patterns. Stems of some genera, such as Ochanostacbys (B) produced fruit as often as the overall average (Ochanostachys fruit frequency $=0.04$, overall genera mean fruit frequency $=0.05)$, yet were highly synchronous $(C V=295.8)$. In contrast, other genera such as Girroniera (C) and Artabotrys (D) produced fruit in almost every month, either by fruiting often (Girroniera; fruit frequency $=0.13$ ) or exhibiting low syncbrony among stems (Artabotrys, $\mathrm{CV}=65.7)$.

(fruit frequency $=0.13, \mathrm{CV}=64.4$ ) however, genera such as Artabotrys, only remained constantly available due to low synchrony among stems $(\mathrm{CV}=65.7)$, rather than by stems fruiting often (fruit frequency $=0.04)$. All three genera had comparable stem density $(\sim 3-5$ stems per ha).

ECOLOGICAL CHARACTERISTICS OF GIBbON FrUit USE.-The AICc comparisons gave the top model 89 percent of the model weight (Table 3), which performed substantially better than the intercept only null model ( $\triangle \mathrm{AICc}=38 ; 0 \%$ model weight). This top model consisted of three predictors: synchrony, stem density, and fruit

TABLE 3. Akaike's information criterion (AICc) model comparison results, showing the top two models and the null model.

\begin{tabular}{lccccc}
\hline Model components & df & Log-likelihood & AICc & $\Delta$ AICc & Weight \\
\hline Stem density, fruit & 5 & -121.98 & 254.36 & 0.00 & 0.89 \\
$\quad$ frequency, synchrony & & & & & \\
Synchrony & 3 & -127.10 & 260.36 & 6.00 & 0.04 \\
Intercept (Null Model) & 2 & -144.16 & 292.41 & 38.04 & 0.00 \\
\hline
\end{tabular}

frequency. The next highest-ranking model included only synchrony ( $\triangle \mathrm{AICc}=6 ; 4 \%$ of model weight). Effect estimates of synchrony, stem density, and fruit frequency were produced in an averaged model, based on AICc weighting of all 20 models, which was heavily biased toward the top two models (comprising over $90 \%$ of model weight).

Stem density (estimate $=0.32, \mathrm{SE}=0.32 ;$ Fig. $3 \mathrm{~A}$ ) and fruit frequency (estimate $=-0.50, \mathrm{SE}=0.38$; Fig. $3 \mathrm{~B}$ ) had only weak reliability as predictors of use of a given genus by $H$. albibarbis. In contrast, synchrony had a reliably negative effect on the amount of predicted use (estimate $=-2.14, \mathrm{SE}=0.71$; Fig. 3C). There was one other reliable predictor in the averaged model (Fig. 4): $d b h$ (estimate $=1.75, \mathrm{SE}=0.80$ ); although our AICc model comparison indicated that it was of low relative importance (receiving only $2 \%$ model weight when occurring with the top two predictors, stem density and fruit frequency, and ranked lower than the null model when occurring as a lone predictor). This likely reflects the small effect size of $d b h$.

To establish whether Ficus was solely responsible for the strong negative effect of synchrony on $H$. albibarbis food use, we re-ran the analysis with Ficus excluded. The order of models favored by AICc comparison did not change (additionally, the model with synchrony alone increased from 4\% weight to $9 \%$ weight) and the averaged model estimate for synchrony was still well supported (estimate $=-1.76, \mathrm{SE}=0.68$ ).

We were also concerned that genera that only fruited once may have had a high synchrony value as an artifact, erroneously driving this result. We therefore re-ran our analysis using only genera that fruited at least three times and found no qualitative difference in our results from the full analyses presented here.

\section{DISCUSSION}

The central objective of this study was to identify the ecological and phenological predictors of fruit consumption by Whitebearded gibbons inhabiting a highly variable Southeast Asian forest. We used a model selection approach to identify key characteristics of gibbon fruit use. The results of model comparison based on AICc suggested that only three ecological characteristics were important predictors of resource use: the overall abundance of a genus (stem density), the proportion of time that a genus produced fruit (fruiting frequency), and the extent to which stems within a genus fruited at the same time (synchrony). Further analysis revealed that, of the three most important predictors, only synchrony had a reliable (negative) effect, indicating that gibbons feed more often on genera whose stems fruit out of phase with each other (i.e., low synchrony). Dbh was also found to have a reliable effect estimate, but was a far less useful predictor than synchrony. Although low fruiting synchrony is a well-known characteristic of the most frequently consumed genus (Ficus), we found the same result when Ficus was excluded from the analysis, which suggests that the importance of low fruiting synchrony for gibbons is not due solely to figs.

IMPORTANCE OF FRUITING ASYNCHRONY FOR FRUGIVORES.-Ficus spp. have long been known for their asynchronous phenology, as 


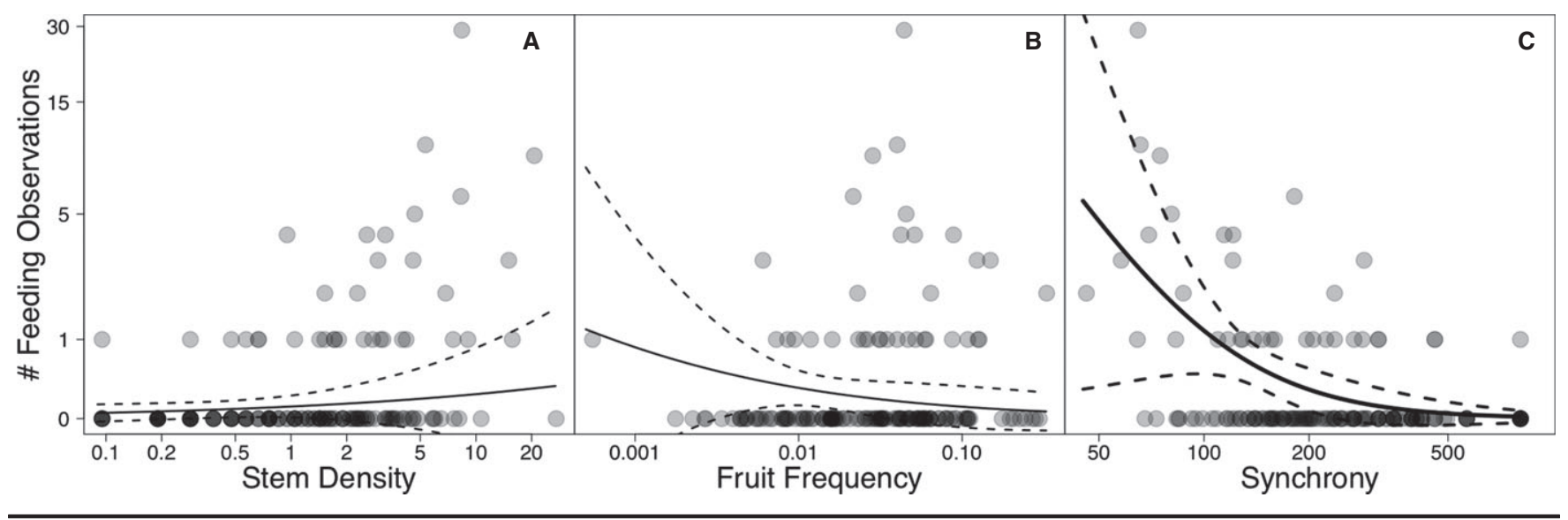

FIGURE 3. Estimated trends for key ecological variables. Number of feeding observations per genus by Hylobates albibarbis as a function of the per genus stem density (A), fruit frequency (B) and syncbrony (C). Axes are displayed in natural log scaling to match the scale used for model fitting. Gray dots are the raw observations and solid curves depict estimated means. Dashed and dotted curves depict 95 percent confidence bands for the mean. Heavy line in $\mathrm{C}$ indicates that the model-averaged confidence intervals for this variable do not include zero. Neither stem density nor fruit frequency had reliable effects on fruit use. In contrast, genera with low synchrony values (high asynchrony) were reliably consumed more often.

\section{Stem Density}

Fruit Frequency

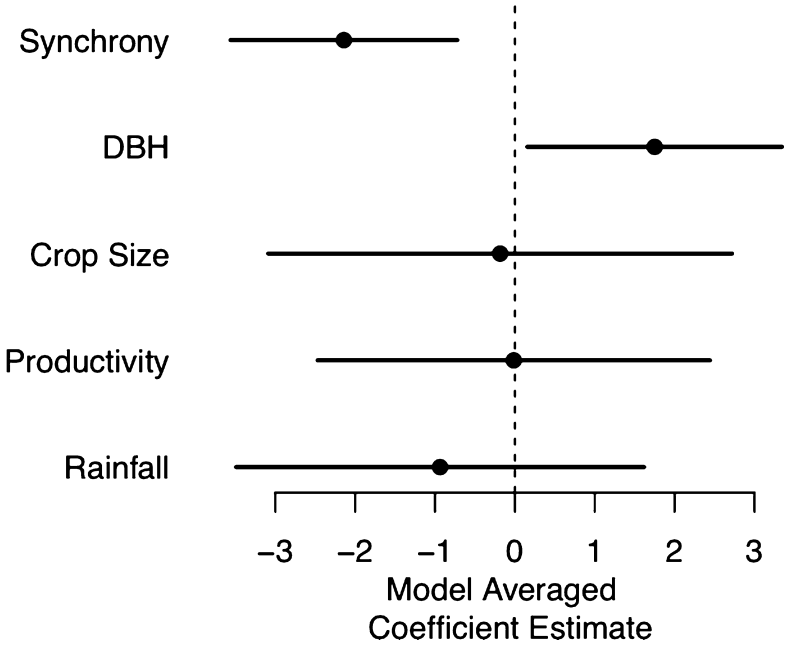

FIGURE 4. Model-averaged coefficient estimates (including 95\% confidence intervals) for averaged models. As these estimates were calculated based on $\log$-transformed data, expected use is proportional to a value of the predictor raised to the coefficient estimate. Coefficient estimates less than zero result in a lower expected count while those greater than zero result in a higher expected count. Coefficient plots such as these depict the direction and relative reliability of each estimate, not the relative effect size. Predictors are displayed in descending order of relative importance assigned by AICc comparison.

well as their role as a heavily used keystone resource for many tropical frugivores (Janzen 1979). Because of this, and due to heavy use of Ficus by gibbons at CPRS (Marshall \& Leighton
2006, Marshall et al. 2009a) we examined whether Ficus alone was responsible for the finding that low fruiting synchrony strongly predicted gibbon feeding observations. Notably, we found that Ficus did not drive this result. The general importance of asynchronous fruiting, beyond solely the genus Ficus, therefore suggests that for some foragers, Ficus may simply be an important example within a larger set of asynchronous food resources. In particular, three of the next four most heavily used genera had comparable synchrony values (Artabotrys (Annonaceae), $\mathrm{CV}=66$; Syzygium (Myrtaceae), $\mathrm{CV}=75$; Diospyros (Ebenaceae) $\mathrm{CV}=81$; see Fig. $3 \mathrm{C}$ ). A diet biased toward genera exhibiting low fruiting synchrony likely buffers animals from food scarcity. Furthermore, because a single genus, such as Ficus, is unlikely to be sufficiently common to solely support large, diverse assemblages of tropical frugivores, vertebrate populations likely also rely on other taxa with low synchrony for persistence (Leighton \& Leighton 1983, Terborgh 1983, Peres 2000). These results suggest that asynchronously fruiting plant genera may be particularly important for habitat restoration of tropical forests and the conservation of frugivore populations that inhabit them. This is likely to be especially important in hyper-variable environments exhibiting prolonged periods of fruit scarcity, such as those found at CPRS.

TAXONOMY, PHENOLOGY AND ASYCHRONY.-Plant genera can offer frugivores constant fruit availability as a result of individual stems either fruiting often (i.e., high fruit frequency) or out of phase with each other (i.e., low synchrony). Our results demonstrate that gibbons prefer to feed on plant genera that provide consistent fruit availability due to fruiting asynchrony rather than those that are consistently available due to high individual fruiting frequency. Because our analyses were conducted at the genus level, low synchrony between stems could have arisen either from asynchrony among all congeners, or asynchrony between synchronously fruiting species. Future work focused specifically on intra- and 
inter-specific fruiting asynchrony within these genera would be valuable for examining alternative explanations for fruiting asynchrony among congeneric plants, which has been hypothesized to reduce competition for dispersers between closely related species (Snow 1965, Wheelwright 1985, van Schaik et al. 1993). Because genera that fruit asynchronously are fed on more often, this phenological strategy might increase the likelihood of seed dispersal. This is probably due at least in part to the fact that they are available during periods of fruit scarcity (Marshall et al. 2009a).

Although both high fruiting frequency and low synchrony would tend to promote availability during times of general scarcity, it is unclear why genera with low fruiting synchrony would be more important to gibbons than those with high fruiting frequency. Perhaps nutritional or metabolic constraints on plant reproduction (or life history tradeoffs) preclude individuals from continuously producing high quality fruit. However, the fruits of some highly used genera, such as those of Ficus, are considered to be of relatively low nutritional quality (Leighton 1993), so alternative reproductive constraints, such as those placed on large crop sizes, may be operating as well. Regardless, genera whose stems produce attractive crops (whether due to high nutritional quality or large quantities of fruit) may represent optimal food sources for some frugivores if they are consistently available due to partitioning of fruiting events between individuals. Work comparing the morphological and chemical differences between fruits produced under asynchronous and continuous phenologies, as well as crop sizes associated with these reproductive habits, is needed.

\section{CONCLUSION}

Feeding behavior of a tropical frugivore is influenced by general ecological and phenological characteristics of plant resources. While there was no evidence that gibbons avoided mast fruiting genera, which are characterized by high values of forest productivity, their diets were biased toward genera with particularly low inter-individual fruiting synchrony. By incorporating a range of ecological characteristics and a large number of genera, we determined that asynchronous fruiting, which is well-recognized from Ficus studies, may be important across a broader range of plant taxa. Considering the amount of variation in the ecological characteristics of plants and the diversity of frugivores, the patterns we report for gibbons likely do not apply to all frugivores. One possible reason comes from gibbons' preference for traveling, and to a lesser extent feeding, in upper canopy trees (Cannon \& Leighton 1994, Marshall et al. 2009b), which as a whole fruit much less frequently than understory trees (Sakai 2002). This could potentially make asynchronous fruit sources particularly more important for these canopy feeders, than for frugivorous taxa that feed predominantly on frequently fruiting understory trees and shrubs (e.g., many birds) or those that can migrate in response to spatial and temporal variation in food availability (e.g., orangutans, hornbills, pigs; Leighton \& Leighton 1983, Curran \& Leighton 2000, Marshall et al. 2014). Additional research on the ecological and phenological characteristics influencing fruit consumption by other frugivores would help determine how broadly our results apply, as well as deepen our understanding of frugivore ecology and contribute to conservation and restoration efforts.

\section{ACKNOWLEDGMENTS}

We gratefully acknowledge M. Grote for statistical advice. Permission to conduct research at Gunung Palung National Park was kindly granted by the Indonesian Institute of Sciences (LIPI), the State Ministry of Research and Technology (RISTEK), the Directorate General for Nature Conservation (PHKA) and the Gunung Palung National Park Bureau (BTNGP). A.J.M. gratefully acknowledges the financial support of the Louis Leakey Foundation, the Orangutan Conservancy, the Hellman Foundation, the Mohamed bin Zayed Foundation, the Seneca Park Zoo, and the University of California, Davis, U.S.A. H.U.W. and A.J.M. gratefully acknowledge support of a University Research Fund Grant and a Faculty Strategic Research Grant from Victoria University of Wellington, New Zealand. A.J.M. thanks Universitas Tanjungpura (UNTAN), his counterpart institution in Indonesia since 1996, and gratefully acknowledges the assistance and support of the many students, researchers, and field assistants who worked at the Cabang Panti Research Station over the past two decades, particularly Albani, M. Ali A. K., L. G. Bell, Busran A. D., E. Tang, Hanjoyo, J. R. Harting, S. M. Jaffe, S. R. Lemoine, Rhande, and J. R. Sweeney. We thank Wahyu Susanto for checking our Indonesian abstract. We thank several anonymous reviewers whose comments on a previous version greatly improved this paper.

\section{SUPPORTING INFORMATION}

Additional Supporting Information may be found in the online version of this article:

TABLE S1. List of models used in AICc model comparison and averaging.

TABLE S2. Correlation coefficients of continuous predictor variables.

TABLE S3. List of 154 genera considered in this analysis, along with their associated values for each predictor variable.

\section{LITERATURE CITED}

Almeida-Neto, M., F. Campassi, M. Galetti, P. Jordano, and A. Oliveira. 2008. Vertebrate dispersal syndromes along the Atlantic forest: Broadscale patterns and macroecological correlates. Glob. Ecol. Biogeogr. 17: 503-513.

APG II. 2003. An update of the Angiosperm Phylogeny Group classification for the orders and families of flowering plants: APG II. Bot. J. Linn. Soc. 141: 399-436.

BARTOŃ, K. 2012. MuMIn: multi-model inference. R package version 0.12.2. Available at: http://r-forge.r-project.org/projects/mumin/.

Beaudrot, L., M. Rejmánek, and A. J. Marshall. 2013. Dispersal modes affect tropical forest assembly across trophic levels. Ecography 36: 984-993.

Blendinger, P. G., AND M. Villegas. 2011. Crop size is more important than neighborhood fruit availability for fruit removal of Eugenia uniflora (Myrtaceae) by bird seed dispersers. Plant Ecol. 212: 889-899. 
BLundell, A. 1996. A preliminary checklist of mammals at Cabang Panti research station, Gunung Palung National Park, West Kalimantan. Trop. Biodiv. 3: 251-259.

Buckiand, S., D. Anderson, K. Burnham, J. LaAke, and D. Borchers. 2001. Introduction to distance sampling: Estimating abundance of biological populations. Oxford University Press, New York, NY.

Buckland, S., A. Plumptre, L. Thomas, and E. Rexstad. 2010. Design and analysis of line transect surveys for primates. Int. J. Primatol. 31: 833847.

Burnham, K. P., and D. R. Anderson. 2002. Model selection and multimodel inference: A practical information-theoretic approach. Springer, New York, NY.

Burns, K. 2004. Scale and macroecological patterns in seed dispersal mutualisms. Glob. Ecol. Biogeogr. 13: 289-293.

Cannon, C. H., L. M. Curran, A. J. Marshall, and M. Leighton. 2007 a. Beyond mast-fruiting events: Community asynchrony and individual dormancy dominate woody plant reproductive behavior across seven Bornean forest types. Curr. Sci. 93: 1558-1566.

Cannon, C. H., L. M. Curran, A. J. Marshall, and M. Leighton. 2007 b. Long-term reproductive behaviour of woody plants across seven Bornean forest types in the Gunung Palung National Park (Indonesia): Suprannual synchrony, temporal productivity and fruiting diversity. Ecol. Lett. 10: 956-969.

Cannon, C. H., And M. Leighton. 1994. Comparative locomotory ecology of gibbons and macaques: Selection of canopy elements for crossing gaps. Am. J. Phys. Anthropol. 93: 505-524.

Cannon, C. H., and M. Leighton. 2004. Tree species distributions across five habitats in a Bornean rain forest. J. Veg. Sci. 15: 257-266.

Carlo, T. A., and J. M. Morales. 2008. Inequalities in fruit-removal and seed dispersal: Consequences of bird behaviour, neighbourhood density and landscape aggregation. J. Ecol. 96: 609-618.

Chapman, C. A., L. J. Chapman, R. Wangham, K. Hunt, D. Gebo, and L. GARDNER. 1992. Estimators of fruit abundance of tropical trees. Biotropica 24: 527-531.

Chazdon, R. L., S. Careaga, C. Webb, and O. Vargas. 2003. Community and phylogenetic structure of reproductive traits of woody species in wet tropical forests. Ecol. Monogr. 73: 331-348.

Cipollini, M. L., AND D. J. Levey. 1997. Secondary metabolites of fleshy vertebrate-dispersed fruits: Adaptive hypotheses and implications for seed dispersal. Am. Nat. 150: 346-372.

Conktin-Brittain, N. L., R. W. Wrangham, and K. D. Hunt. 1998. Dietary response of chimpanzees and cercopithecines to seasonal variation in fruit abundance. II. Macronutrients. Int. J. Primatol. 19: 971-998.

Curran, L., AND M. Leighton. 2000. Vertebrate responses to spatiotemporal variation in seed production of mast-fruiting Dipterocarpaceae. Ecol. Monogr. 70: 101-128.

Davies, T. J., E. M. Wolkovich, N. J. Kraft, N. Salamin, J. M. Allen, T. R. Ault, J. L. Betancourt, K. Bolmgren, E. E. Cleland, and B. I. CoOK. 2013. Phylogenetic conservatism in plant phenology. J. Ecol. 101: $1520-1530$.

Felton, A. M., A. Felton, J. T. Wood, W. J. Foley, D. Raubenheimer, I. R. Waldis, and D. B. Lindenmayer. 2009. Nutritional ecology of Ateles chamek in lowland Bolivia: How macronutrient balancing influences food choices. Int. J. Primatol. 30: 675-696.

Felton, A., A. Felton, J. Wood, And D. Lindenmayer. 2008. Diet and feeding ecology of Ateles chamek in a Bolivian semihumid forest: The importance of Ficus as a staple food resource. Int. J. Primatol. 29: 379-403.

Fischer, K. E., And C. A. Chapman. 1993. Frugivores and fruit syndromes: Differences in patterns at the genus and species level. Oikos 66: 472-482.

Fleming, T. H. 1992. How do fruit- and nectar- feeding birds and mammals track their food resources? In M. D. Hunter, T. Ohgushi, and P. W. Price (Eds.). Effects of resource distribution on animal plant interactions, pp. 355-393. Academic Press, New York, NY.
Fredriksson, G. M., AND S. A. Wich. 2006. Frugivory in sun bears (Helarctos malayanus) is linked to El Niño-related fluctuations in fruiting phenology, East Kalimantan, Indonesia. Biol. J. Linn. Soc. 89: 489-508.

Garcia, D., and R. Ortiz-Pulido. 2004. Patterns of resource tracking by avian frugivores at multiple spatial scales: Two case studies on discordance among scales. Ecography 27: 187-196.

Gautier-Hion, A., J. M. Duplatier, R. Quris, F. Feer, C. Sourd, G. Decoux, L. H. Emmons, C. Erard, P. Hecketsweiler, A. Moungazi, C. RousSilhon, And J. M. Thiolday. 1985. Fruit characters as a basis of fruit choice and seed dispersal in a tropical forest vertebrate community. Oecologia 65: 324-337.

Gupta, A., And D. J. Chivers. 1999. Biomass and use of resources in south and south-east Asian primate communities. In J. G. Fleagle, C. Janson, and K. Reed (Eds.). Primate communities, pp. 38-54. Cambridge University Press, Cambridge, UK.

Hanya, G. 2005. Comparisons of dispersal success between the species fruiting prior to and those at the peak of migrant frugivore abundance. Plant Ecol. 181: 167-177.

Harvey, P. H., and M. Pagel. 1991. Comparative method in evolutionary biology (POD). Oxford University Press, Oxford, UK.

Howe, H. F., And J. Smallwood. 1982. Ecology of seed dispersal. Annu. Rev. Ecol. Syst. 13: 201-228.

Janson, C. H. 1983. Adaptation of fruit morphology to dispersal agents in a neotropical forest. Science 219: 187-189.

Janzen, D. H. 1979. How to be a fig. Annu. Rev. Ecol. Syst. 10: 13-51.

Johnson, J. B., And K. S. OmLand. 2004. Model selection in ecology and evolution. Trends Ecol. Evol. 19: 101-108.

Kelly, C., And A. Purvis. 1993. Seed size and establishment conditions in tropical trees. Oecologia 94: 356-360.

Kier, G., J. Mutke, E. Dinerstein, T. H. Ricketts, W. Küper, H. Kreft, AND W. Barthlott. 2005. Global patterns of plant diversity and floristic knowledge. J. Biogeogr. 32: 1107-1116.

KNIGHT, R. S., AND W. R. Siegfried. 1983. Interrelationships between type, size and color of fruits and dispersal in southern African trees. Oecologia 56: 405-412.

Korine, C., E. K. Kalko, and E. A. Herre. 2000. Fruit characteristics and factors affecting fruit removal in a Panamanian community of strangler figs. Oecologia 123: 560-568.

Laman, T.G., J. C. Gaither, And D. E. Lukas. 1996. Rain forest bird diversity in Gunung Palung National Park, West Kalimantan, Indonesia. Trop. Biodiv. 3: 281-296.

Lambert, F. R., and A. G. Marshall. 1991. Keystone characteristics of birddispersed Ficus in a Malaysian lowland rain forest. J. Ecol. 79: 793809.

Leighton, M. 1993. Modeling dietary selectivity by Bornean orangutans: Evidence for integration of multiple criteria in fruit selection. Int. J. Primatol. 14: 257-313.

Leighton, M., And D. Leighton. 1983. Vertebrate responses to fruiting seasonality within a Bornean rain forest. In S. L. Sutton, T. C. Whitmore, and A. C. Chadwick (Eds.). Tropical rain forest: Ecology and resource management, pp. 181-196. Blackwell Scientific Publications, Oxford, UK.

Lomáscolo, S. B., D. J. Levey, R. T. Kimball, B. M. Bolker, and H. T. AlBORn. 2010. Dispersers shape fruit diversity in Ficus (Moraceae). Proc. Natl Acad. Sci. 107: 14668-14672.

MacKinnon, K., G. Hatta, H. Halim, and A. Mangalik. 1996. The ecology of Kalimantan: Indonesian Borneo. Periplus Editions, Singapore.

Marshall, A. J. 2004. Population ecology of gibbons and leaf monkeys across a gradient of Bornean forest types. PhD Dissertation. Harvard University, Cambridge, MA.

Marshall, A. J. 2009. Are montane forests demographic sinks for Bornean white-bearded gibbons Hylobates albibarbis? Biotropica 41: 257-267.

Marshall, A. J. 2010. Effect of habitat quality on primate populations in Kalimantan: Gibbons and leaf monkeys as case studies. In S. Gursky, and 
J. Supriatna (Eds.). Indonesian primates, pp. 157-177. Springer, New York, NY.

Marshall, A. J., L. Beaudrot, and H. U. Wittmer. 2014. Responses of primates and other frugivorous vertebrates to plant resource variability over space and time at Gunung Palung National Park. Int. J. Primatol. Doi: 10.1007/s10764-014-9774-4. [Epub ahead of print]

Marshall, A. J., C. M. Boyko, K. L. Feilen, R. H. Boyko, and M. LeighTON. 2009a. Defining fallback foods and assessing their importance in primate ecology and evolution. Am. J. Phys. Anthropol. 140: 603-614.

Marshall, A. J., C. H. Cannon, and M. Leighton. 2009b. Competition and niche overlap between gibbons (Hylobates albibarbis) and other frugivorous vertebrates in Gunung Palung National Park, West Kalimantan, Indonesia. In S. Lappan, and D. J. Whittaker (Eds.). The gibbons: New perspectives on small ape socioecology and population biology, pp. 161-188. Springer, New York.

Marshall, A. J., And M. Leighton. 2006. How does food availability limit the population density of white bearded gibbons? In G. Hohmann, M. M. Robbins, and C. Boesch (Eds.). Feeding ecology in apes and other primates: Ecological, physical, and behavioral aspects, pp. 313-335. Cambridge University Press, Cambridge, UK.

Marshall, A. J., and S. A. Wich. 2013. Characterization of primate environments through assessment of plant phenology. In E. Sterling, N. Bynum, and M. Blair (Eds.). Primate ecology and conservation, pp. 103127. Oxford University Press, Oxford, UK.

Marshall, A. J., AND R. WRAnGHam. 2007. Evolutionary consequences of fallback foods. Int. J. Primatol. 28: 1219-1235.

McConkey, K. R., F. Aldy, A. Ario, And D. J. Chivers. 2002. Selection of fruit by gibbons (Hylobates muelleri $\times$ agilis) in the rain forests of Central Borneo. Int. J. Primatol. 23: 123-145.

McConkey, K. R., A. Ario, F. Aldy, And D. J. Chivers. 2003. Influence of forest seasonality on gibbon food choice in the rain forests of Barito Ulu, Central Kalimantan. Int. J. Primatol. 24: 19-32.

McKey, D. 1975. The ecology of coevolved seed dispersal systems. In L. E. Gilbert, and P. H. Raven (Eds.). Coevolution of animals and plants, pp. 158-191. The ecology of coevolved seed dispersal systems, University of Texas Press, Austin, Texas.

Paoli, G. D., L. M. Curran, and D. R. ZaK. 2006. Soil nutrients and beta diversity in the Bornean Dipterocarpaceae: Evidence for niche partitioning by tropical rain forest trees. J. Ecol. 94: 157-170.

Peres, C. A. 2000. Identifying keystone plant resources in tropical forests: The case of gums from Parkia pods. J. Trop. Ecol. 16: 287-317.

Poulin, B., S. J. Wright, G. Lefebvre, and O. Calderon. 1999. Interspecific synchrony and asynchrony in the fruiting phenologies of congeneric bird-dispersed plants in Panama. J. Trop. Ecol. 15: 213-227.
Primack, R. B., and R. Corlett. 2005. Tropical rain forests: An ecological and biogeographical comparison. Blackwell Pub., Malden, MA.

R core Development Team 2012. R: A language and environment for statistical computing. R Foundation for Statistical Computing. Vienna, Austria.

SAKAI, S. 2002. General flowering in lowland mixed dipterocarp forests of South-east Asia. Biol. J. Linn. Soc. 75: 233-247.

van Schaik, C. P., J. W. Terborgh, and S. J. Wright. 1993. The phenology of tropical forests: Adaptive significance and consequences for primary consumers. Annu. Rev. Ecol. Syst. 24: 353-377.

da Silva, J. M. C., and M. Tabarelu. 2000. Tree species impoverishment and the future flora of the Atlantic forest of northeast Brazil. Nature 404: 72-74.

SNow, D. 1965. A possible selective factor in the evolution of fruiting seasons in tropical forest. Oikos 15: 274-281.

Stevenson, P., And A. Link. 2010. Fruit preferences of Ateles belzebuth in Tinigua Park, Northwestern Amazonia. Int. J. Primatol. 31: 393-407.

Terborgh, J. 1983. Five new world primates: A study in comparative ecology. Princeton University Press, Princeton, N.J..

Terborgh, J., N. Pitman, M. Silman, H. Schichter, and P. Núñez. 2002. Maintenance of tree diversity in tropical forests. In D. J. Levey, W. R. Silva, and M. Galetti (Eds.). Seed dispersal and frugivory: Ecology, evolution and conservation, pp. 1-17. CABI Publishing, Wallingford, UK.

Thies, W., and E. K. KalKo. 2004. Phenology of neotropical pepper plants (Piperaceae) and their association with their main dispersers, two short-tailed fruit bats, Carollia perspicillata and C. castanea (Phyllostomidae). Oikos 104: 362-376.

van Schaik, C. 1986. Phenological changes in a Sumatran rain forest. J. Trop. Ecol. 2: 327-347.

Voigt, F. A., B. Bleher, J. Fietz, J. U. Ganzhorn, D. Schwab, and K. BohNING-GAESE. 2004. A comparison of morphological and chemical fruit traits between two sites with different frugivore assemblages. Oecologia 141: 94-104.

WaLKer, J. S. 2007. Dietary specialization and fruit availability among frugivorous birds on Sulawesi. Ibis 149: 345-356.

Wheelwright, N. T. 1985. Competition for dispersers, and the timing of flowering and fruiting in a guild of tropical trees. Oikos 44: 465-477.

Wich, S., AND C. V. van SchaIK. 2000. The impact of El Nino on mast fruiting in Sumatra and elsewhere in Malesia. J. Trop. Ecol. 16: 563-577.

Wrangham, R. W., N. L. Conklin-Brittain, and K. D. Hunt. 1998. Dietary response of chimpanzees and cercopithecines to seasonal variation in fruit abundance. I. Antifeedants. Int. J. Primatol. 19: 949-970. 